\title{
CT Findings in Late-Onset Epilepsy
}

\author{
V. de la Sayette, R. Cosgrove, D. Melanson and R. Ethier
}

\begin{abstract}
We reviewed the CT findings of 387 patients with new-onset seizures after the age of 50 . Seizures were generalized in 212 patients, focal in 160, and indeterminant in 15 . CT scanning revealed cerebral atrophy in 113 cases, ischemic lesions in 75 , cerebral neoplasms in 20 , and no abnormality in 177 cases. Tumours were found in only three patients with generalized seizures, and all three had focal neurological deficits at the time of CT diagnosis, while 17 neoplasms were discovered in patients with a focal seizure disorder. The majority of patients with late-onset epilepsy have a normal CT scan with cerebral atrophy being the most common abnormality detected. Cerebral vascular disease appears to be the most frequently identified cause of late-onset epilepsy, while cerebral neoplasms are uncommon.
\end{abstract}

RÉSUMÉ: Constatations au CT scan dans l'épilepsie d'apparition tardive. Nous avons revu 387 CT scans de patients, âgé de 50 ans et plus, souffrant d'épilepsie de novo. Les crises étaient généralisées chez 212 patients, focales chez 160 et de nature indéterminée chez 15 . Outre l'âge et le caractère récent de l'épilepsie, les patients retenus pour cette étude étaient exempts de tout antécédent neurologique ou neurochirurgical. Sur les 387 patients sélectionnés, 113 présentaient une atrophie cérébrale, 75 des lésions vasculaires, 20 des néoplasies et enfin 177 ne présentaient aucune anomalie. La présence de tumeur fut relevée seulement chez 3 patients souffrant d'épilepsie généralisée et tous 3 présentaient un déficit neurologique lors de l'étude par CT, alors que 17 néoplasies ont été découvertes chez les patients présentant une épilepsie focale. La majorité des patients souffrant d'épilepsie après 50 ans ont un CT normal, l'atrophie cérébrale y étant l'anomalie la plus communément rencontrée. Une maladie cérébrovasculaire apparaît être la cause la plus fréquemment identifiée dans l'émergence de l'épilepsie tardive (50 ans et plus), alors que les néoplasies sont plutôt rares.

Can. J. Neurol. Sci. 1987; 14:286-289

Epilepsy beginning in late adult life is uncommon' but may be caused by a variety of disorders including cerebrovascular disease, brain tumours, degenerative and inflammatory cerebral processes or metabolic disturbances. However, only limited information is available concerning the clinical characteristics and causes of late-onset epilepsy. The importance of establishing an etiological diagnosis and excluding an expanding intracerebral lesion as the cause of the seizure is well accepted. In addition to clinical and electrophysiological data, computed tomography (CT) is commonly employed to investigate epilepsy in the elderly. We have reviewed the clinical and CT findings of 387 elderly patients (older than 50) with new-onset seizures in an attempt to establish clinical and radiological correlations in late-onset epilepsy and to examine the role of $\mathrm{CT}$ scanning in this condition.

\section{Materials AND Methods}

In a review of the radiological files of the Montreal Neurological Hospital from 1978 to 1984 , we found 387 cases of late-onset epilepsy. There were 219 men (mean age, 61.8 years) and 168 women (mean age, 62 years). One hundred and eighty-two (182) patients had their first seizure between the ages of 50-59 (Group A), while 205 patients experienced their first seizure at 60 years of age or older (Group B). There was no sex difference between groups.

The majority of CT scans were performed on out-patients referred by private neurologists for new-onset seizures in previously healthy individuals. Patients with known antecedent neurological disease, previous seizures (even in childhood), or a history of remote cranial trauma or neurosurgical intervention were excluded. Doubtful cases of epilepsy, either on a clinical or electroencephalographic (EEG) basis were excluded. Clinical and electrophysiological information was obtained from chart review and by direct communication with the referring physician. Only 19 patients had associated focal neurological deficit at the time of their first seizure and CT scan.

Seizure type was classified as generalized, partial (simple, complex or with secondary generalization) or indeterminate according to the international classification of Gastaut. Patients with both partial and generalized seizures were classified as partial. Electrophysiological correlation was not attempted because complete EEG data was not available on all patients.

From the Departments of Neurology, Neurosurgery and Radiology, Montreal Neurological Hospital, Montreal

Received October 23, 1986. Accepted in final form March 14, 1987

Reprint requests to: Dr. Denis Melanson, Montreal Neurological Hospital, 380I University Street, Montreal, Quebec H3A 2B4 
All scans were performed on an EMI 1010 Head Scanner ( 160 $x 160$ matrix) with systematic study from vertex to foramen magnum at $10 \mathrm{~mm}$ intervals. Contrast enhancement was not used routinely, except in patients presenting partial epilepsy and in those where the initial plain CT showed ventricular asymmetry. All scans were reviewed by one of our radiologists and examined for evidence of neoplasia, ischemic lesions, cerebral atrophy, ventricular asymmetry or other abnormalities. Ischemic lesions were further classified as: 1) lacunar infarcts: deeply situated, discrete, low-density lesions less than $1 \mathrm{~cm}$ in diameter; 2) cerebral infarcts: low-density lesions greater than $1 \mathrm{~cm}$ in diameter; 3 ) subcortical arteriosclerotic encephalopathy (SAE); ill-defined, periventricular low-density lesions often in conjunction with lacunes.

Cerebral atrophy was deemed present on the basis of subjective data, given the age of the patient. Regression of the brain with aging is a normal process but there is marked individual variation in the degree of involutional changes. ${ }^{2}$ Thus, the appreciation of brain atrophy as a significant finding remains a matter of personal interpretation. In our analysis, "atrophy more than expected for age" comes from the reviewer's experience (DM) of more than 60,000 head scans, and not from any volumetric measurements.

\section{Results}

Of 387 patients included in the study, $212(54.6 \%)$ presented with generalized seizures of which $35(9 \%)$ were purely nocturnal. Focal seizures were present in $160(41.2 \%)$ patients: $82(21.4 \%)$ had partial-simple seizures, $56(14.1 \%)$ partial-complex and 22 (5.7\%) had partial seizures with secondary generalization. Fifteen $(4.2 \%)$ cases had seizures of an indeterminate nature (Table 1).

CT scanning revealed cerebral atrophy in 113 cases; 8 cases were extremely severe and 4 were predominately unilateral. Ischemic lesions were present in 75 cases, of which there were 19 cerebral infarcts, 28 lacunar infarcts and 37 arteriosclerotic leukoencephalopathies. Primary cerebral tumours or metastases were seen in 20 cases. Excluding unilateral cerebral atrophy, 18 cases of significant ventricular asymmetry were seen, of which 11 had a follow-up study at three months which failed to reveal any underlying cause of the asymmetry. Other lesions detected included 3 cases of orbito-frontal hypodensities suggestive of remote trauma; one granuloma, one small venous malformation, one normal-pressure hydrocephalus and one case with regular punctate cortical hypodensity the origin of which was unclear. Subarachnoid hemorrhage and intracerebral or subdural hematoma was not seen in any case. Finally, $177 \mathrm{CT}$ scans showed no abnormality.

\begin{tabular}{lrrrr}
\hline Table 1: Seizure type and age group distribution \\
\hline \hline & \multicolumn{1}{c}{ Group A } & \multicolumn{1}{c}{ Group B } \\
\hline Generalized Seizures: Total & 107 & $58.8 \%$ & 105 & $51.2 \%$ \\
Generalized Seizures: Nocturnal & 17 & $9.3 \%$ & 11 & $8.3 \%$ \\
Focal Seizures: Total & 66 & $36.3 \%$ & 94 & $45.9 \%$ \\
Focal Seizures: Simple & 28 & $15.4 \%$ & 54 & $26.3 \%$ \\
Focal Seizures: Complex & 32 & $17.6 \%$ & 24 & $11.7 \%$ \\
Secondary generalization & 6 & $3.3 \%$ & 16 & $7.9 \%$ \\
Seizures of undetermined nature & 9 & $4.9 \%$ & 6 & $2.9 \%$ \\
\hline
\end{tabular}

Group A (age 50-59) Of 107 patients with generalized seizures; 60 had no abnormality on CT, 27 demonstrated cerebral atrophy, 15 had ischemic lesions and only 3 had a tumour. There was one meningioma and one metastasis but both of these tumours were associated with obvious neurological deficit at the time of their first generalized convulsion. The third tumour was a glioblastoma multiforme. The initial CT plain and with infusion revealed only ventricular asymmetry and the EEG recording was normal. The diagnosis was made only 7 months later when CT revealed an enhancing lesion of the left temporal lobe at a time when the patient had focal neurological deficit and seizures that had become focal-motor. Of 66 patients with partial seizures, 35 had no abnormality on CT, 14 demonstrated cerebral atrophy, 6 had ischemic lesions and 11 had a tumour. There were 5 meningiomas, 3 low-grade astrocytomas, 2 glioblastomas and I metastasis. One patient with a meningioma, one with an astrocytoma and both patients with glioblastoma had focal neurological deficit at the time of their CT scan (Table 2).

Group B (60 years or older) 105 patients had generalized seizures of which 40 had a normal CT, 42 demonstrated cerebral atrophy and 24 had ischemic lesions. No neoplastic lesions were seen. Of 94 patients with partial seizures, 35 had no abnormality on CT, 25 demonstrated cerebral atrophy, 23 had ischemic lesions and 6 had cerebral neoplasms including 2 meningiomas, 2 metastases, 1 low-grade astrocytoma and 1 glioblastoma. Only the patient with the glioblastoma had focal neurological deficit at the time of his CT scan (Table 3).

A comparison of Group A and Group B patients with respect to seizure-type and CT findings is presented in Table 4 .

\section{Discussion}

Seizures in previously healthy elderly patients are rare but may be caused by a variety of disorders. In addition to clinical and electrophysiological data, CT scanning is commonly used to facilitate accurate etiological diagnosis. Previous studies of adult epileptic populations using $\mathrm{CT}$ have demonstrated abnormalities in nearly $55 \%$ of patients. ${ }^{3}$ However most series have failed to distinguish between elderly and middle-aged patients

Table 2: Group A: Radiological findings considering the types of seizures

I Generalized seizures except nocturnal.

II Nocturnal generalized seizures.

III Simple partial seizures.

IV Complex partial seizures.

V Secondary generalized seizures.

VI Undetermined seizures.

\begin{tabular}{lcccccccc}
\hline & & I & II & III & IV & V & VI & TOTAL \\
\hline Atrophy & $\times$ & $21^{*}$ & $6^{*}$ & 7 & 6 & 1 & 4 & 45 \\
SAE** & $\times$ & 4 & 1 & 2 & & & & 7 \\
Lacunes & $\times$ & 6 & 1 & 2 & & & & 9 \\
Infarction & $\times$ & 4 & & & 1 & 2 & & 7 \\
Tumours & & 3 & & 4 & 4 & 3 & & 14 \\
Other lesions & + & 5 & 1 & 1 & 5 & & 2 & 14 \\
Normal & & 50 & 10 & 18 & 16 & 1 & 3 & 98 \\
\hline
\end{tabular}

* 1 focal atrophy.

** Subcortical arteriosclerotic encephalopathy.

$\times$ Vascular lesions frequently associated: Atrophy not considered if associated with vascular lesion.

+11 ventricular asymmetry, 1 granuloma, 2 remote trauma. 
or have focused specifically on the incidence of a particular causative factor. Earlier studies of late-onset epilepsy have been limited by their lack of CT data or their small size.

In our series of 387 patients, $212(54.8 \%)$ had generalized seizures while $160(41.3 \%)$ had partial seizures. These figures compare favorably with previously reported series of late-onset epilepsy. ${ }^{4-11}$

Tumours have been estimated to occur in approximately $10-15 \%$ of late-onset epilepsy and it is generally accepted that this number increases in patients with focal seizures. ${ }^{12}$ In our series, a cerebral neoplasm was found as the cause of seizures in only $5.2 \%$ of patients: $7.7 \%$ in Group A ( $50-59$ years); $2.9 \%$ in Group B (older than 60 years).

Of patients with generalized seizures, only $1.4 \%$ were found to have a cerebral neoplasm. No tumours were found in patients with generalized seizures older than 60 and only 3 detected in the younger age group. In addition, all 3 of these patients had focal neurological deficit at the time of CT diagnosis. Patients with focal seizures had a higher incidence of tumours (10.6\%) especially in the 50-59 years age group (16.7\%). In the older age group the incidence of tumour was $8.4 \%$. This difference is significant at p 0.05 . It would appear therefore, that tumours are more likely present in younger patients with focal seizures.

Cerebrovascular disease is frequently implicated as the most common cause of late onset epilepsy with estimates ranging from $17-52 \%{ }^{6.7}$ Despite the exclusion of patients with previously known cerebrovascular disease, ischemic lesions were seen in $11.5 \%$ of Group A patients and $22.7 \%$ of Group B patients ( $p 0.005$ ) for a total of $17.5 \%$. This compares favourably with a recent study which found $\mathrm{CT}$ evidence of cerebrovascu-

\begin{tabular}{lcrrrrrrr}
\hline \multicolumn{10}{c}{ Table 3: Group B: Radiological findings considering the types of seizures } \\
\hline \hline \multicolumn{1}{l}{} & & I & II & III & IV & V & VI & TOTAL \\
\hline Atrophy & $\times$ & $34^{*}$ & 8 & 16 & $3^{*}$ & 6 & I & 68 \\
SAE** & $\times$ & 15 & 3 & 8 & 1 & 3 & & 30 \\
Lacunes & $\times$ & 8 & 1 & 6 & 1 & 3 & & 19 \\
Infarction & $\times$ & 6 & & 5 & & 1 & 1 & 12 \\
Tumours & & & & 4 & & 2 & & 6 \\
Other lesions & + & 4 & & 3 & 3 & 1 & & 11 \\
Normal & & 33 & 7 & 18 & 16 & 1 & 4 & 79 \\
\hline
\end{tabular}

* I focal atrophy.

** Subcortical arteriosclerotic encephalopathy.

$\times$ Vascular lesions frequently associated: Atrophy not considered if associated with vascular lesion.

+7 ventricular asymmetry, 1 remote trauma, I normal pressure hydrocephalus, 1 venous angioma, I undiagnosed cortical punctate hypodensity.

Table 4: Radiological findings, considering the age group and type of seizures*

\begin{tabular}{lcccc}
\hline \hline & \multicolumn{2}{c}{ Group A } & \multicolumn{2}{c}{ Group B } \\
\cline { 2 - 5 } CT Findings & Generalized & Partial & Generalized & Partial \\
\hline Normal & $60(57.1 \%)$ & $35(53 \%)$ & $40(37.7 \%)$ & $35(37.2 \%)$ \\
Atrophy & $27(25.2 \%)$ & $14(21.2 \%)$ & $42(39.6 \%)$ & $25(26.6 \%)$ \\
Vascular & & & & \\
$\quad$ Lesions & $15(14 \%)$ & $6(9.1 \%)$ & $24(21.7 \%)$ & $23(24.5 \%)$ \\
Tumours & $3(2.8 \%)$ & $11(16.7 \%)$ & $0(0 \%)$ & $6(6.4 \%)$ \\
\hline TOTAL & 105 & 66 & 106 & 89 \\
\hline
\end{tabular}

*Undetermined seizures are excluded. lar disease in $18 \%$ of patients with late onset epilepsy as compared to $2.7 \%$ in an age-matched control group..$^{13}$ The type of ischemic lesion however did not correlate with the seizure pattern.

Cerebral atrophy was the most common CT abnormality detected and seen in $24.7 \%$ of Group A patients and $33.2 \%$ of Group B patients with $29.2 \%$ combined incidence. Although more common in the older age group, its presence, location or severity did not appear to correlate with seizure type and its relationship to late-onset epilepsy is unclear. ${ }^{13-15}$

Marked ventricular asymmetry in the absence of an obvious space-occupying lesion or focal cerebral atrophy was a rare finding and was not associated with a particular seizure pattern. However, an underlying cerebral neoplasm must always be considered and follow-up scans obtained in every case. ${ }^{11.16}$

The CT scan revealed no abnormality in $45 \%$ of cases. Idiopathic late-onset epilepsy is probably the most appropriate diagnosis in this group.

In contrast to earlier studies, ${ }^{3,10,12.17 .18}$ it would appear that brain tumours are a rare cause of new-onset seizures in the elderly. Cerebral neoplasms are however more common in the fifth decade, especially in those patients with partial seizures or focal neurological deficit. Only 3 tumours were identified in patients with generalized seizures and all 3 had focal neurological deficit. In view of the paucity of cerebral tumours and surgically correctable lesions, recent reports have questioned the value of routine $\mathrm{CT}$ scanning in late-onset epilepsy ${ }^{\mid 1.19 .21}$ but this is controversial. ${ }^{9}$ The majority of patients have a normal CT scan and the presence of cerebral atrophy although common, seems to be without particular diagnostic or prognostic influence. Cerebrovascular disease appears to be the most frequently identified cause of late-onset epilepsy although the exact causal relationships require further study.

\section{REFERENCES}

1. Merlis J-K. Epilepsy of late onset. In: Magnus $\mathrm{O}$ and Corentz de Haas AM, eds. Handbook of clinical neurology. 1974;25: 264-170.

2. Lemay M. Radiologic change of the aging brain and skull. AJR 1984; 143: 383-389.

3. Gastaut H, Gastaut J-L. Computerized transverse axial tomography in epilepsy. Epilepsia 1976; 17: 325-336.

4. Bonduelle M, Tallon C, Guillard J. Etude de 61 dossiers d'épilepsie ayant débuté après 60 ans. Sem Hôp Paris 1970; 46: 3141-3444.

5. Carney LR, Hudgins RL, Espinosa RE, Klass DW. Seizures beginning after the age of 60. Arch Intern Med 1969; 124: 707-709.

6. Courjon J, Artru F, Zeskov P. A propos des crises d'épilepsie apparaissant après 60 ans observées en clientèle de neurologie dans un service de neurochirurgie. Sem Hôp Paris 1970; 46: 3129-3132.

7. Feuerstein J, Weber M, Kurtz D, Röhmer F. Etude statistique des crises épileptiques apparaissant après l'âge de 60 ans. Sem Hôp Paris 1970; 46: 3125-3128.

8. Gastaut H. Individualisation des épilepsies dites "bénignes" ou "fonctionnelles" aux différents âges de la vie. Appréciation des variations correspondantes de la prédisposition épileptique à ces âges. Rev EEG Neurophysiol 1981; 11: 346-366.

9. Gastaut H, Michel B, Gastaut J-L, Cerda M. A propos d'une éventuelle épilepsie généralisée secondaire tardive. Apport de la scannographie cérébrale. Rev EEG Neurophysiol 1980; 3: 276-282.

10. Woodstock S, Cosgrove JBR. Epilepsy after the age of 50. Neurol 1964; 14: 34-40.

11. Young AC, Mohr PD, Borg Costanzi J, St. Claire Forbes W. Is routine computerized axial tomography in epilepsy worth while? Lancet Dec. 1982: 1446-1447. 
12. Roberts MA, Godfrey JW, Cairo Fl. Epileptic seizures in the elderly. 1. Aetiology and type of seizures. Age ageing 1982; 11: 24-28.

13. Shorvon SD, Gilliatt RW, Cox TCS, Yu YL. Evidence of vascular disease from CT scanning in late onset epilepsy. J Neurol Neurosurg Psychiatry 1984: 47: 225-230.

14. Gastaut J-L, Farnarier G, Michel B, Serbanescu T, Barrat E, Sambuc R. Etude corrélative des données EEG et scannographiques au cours du vieillissement cérébral normal et pathologique. Rev EEG Neurophysiol 1980; 3: 228-235.

15. Vercelletto $P$, Gastaut J-L. Les épilepsies débutant après 60 ans. Rev EEG neurophysiol 1981; 11: 537-544.
16. Confavreux C, Vighetto A. Boisson D, Aimard G. Devic M. Epilepsie tardive isolée révélatice d'un glioblastome et faux négatifs du scanner. Nouv Presse Med 1981; 10: 2516.

17. Bancaud T. L'épilepsie après 60 ans. Expérience d'un service de neurochirurgie fonctionelle. Sem Hôp Paris 1970: 46: 3138-3140.

18. Vercelletto P, Delobel R. Etude des facteurs étiologiques et pronostiques dans les épilepsies débutant après 60 ans. Sem Hôp Paris 1970; 46: 3133-3137.

19. Gupta K. Epilepsy in the elderly. How far to investigate? Br J Clin Pract 1983: 37: 249-252.

20. Hildick-Smith M. Epilepsy in the elderly. Age aging 1974;3: 203-208. 